\title{
EL MANAGEMENT: UNA ALTERNATIVA DE DIRECCIÓN EMPRESARIAL
}

Lic. ANA MARÍA GUTIÉRREZ HUBY (*)

\section{INTRODUCCIÓN}

Desde el punto de vista general, la capacidad de una institución de crear líderes es más importante que la producción eficiente y barata, la cual siempre puede conseguirse dada una organización y las capacidades humanas. Pero sin un liderazgo emprendedor, responsable y apto, deseoso y capaz de tomar iniciativa, la institución más exitosa no puede mantener su eficiencia y menos incrementarla.

Por ello, el Management es una institución básica y dominante mientras la civilización occidental sobreviva, porque no sólo se funda en la naturaleza del sistema industrial y en las necesidades de las empresas comerciales modernas, a las cuales el sistema industrial debe confiar sus recursos productivos, tanto materiales como humanos; sino que también es la expresión de ciertas creencias básicas de la sociedad occidental. Es también, expresión de la creencia de que el cambio económico se convertirá en la máquina más poderosa para propulsar el mejoramiento humano y la justicia social.

¿Cuál es entonces la clave para que una empresa tenga éxito? A finales del siglo XIX y durante parte del siglo XX, la aplicación del Modelo Clásico de Administración creado por Frederick Taylor en los Estados Unidos, y por Henry Fayol en Francia, determi-naron los factores que impulsaron el éxito de las empresas, los cuales fueron el tamaño, las funciones claramente definidas, la especialización y el control. Cuando más grande era la empresa, lograba mayor eficacia, pues crecía su capacidad de apalancar capital y su influencia sobre los proveedores y clientes. Por razones de eficacia, las tareas se dividían y subdividían, y las funciones y niveles de autoridad de las personas eran claros y terminantes. Se crearon especialidades y subespecialidades, de modo que cada área funcional de la organización se convirtió en una disciplina por derecho propio. Sobre todo, se necesitaba un férreo control para garantizar que todas las partes de la organización obtuvieran los resultados necesarios e integren todas las piezas con la finalidad de producir productos o servicios.

Pero el desarrollo de la empresa es siempre autodesarollo de personas. Es inútil que la empresa se vanagloreé y pretenda asumir la responsabilidad del desarrollo de un individuo. La responsabilidad correspona la propia persona, a sus cualidades y sus esfuerzos. Ninguna empresa puede reemplazar con sus esfuerzos los intentos de autodesarollo del individuo, y mucho menos está obligada a hacerlo. Proceder de este modo implica no sólo un paternalismo injustificado, sino que también constituye una pretensión absurda.

En definitiva, de su amplia, sólida y continua formación nació un pensamiento

(*)Docente Asociado y Directora de la Biblioteca de la Facultad de Ciencias Contables de la UNMSM 
unitario y polifacético a la vez, renuente a dejarse encapsular. Primero, analizó la filosofía social, luego estudió las organizaciones de la sociedad industrial y al final desembocó en el management.

\section{NACE UNA NUEVA FILOSOFÍA}

Pero sería interesante hacerse la pregunta ¿cómo nació el Management?

El Management tiene su origen en investigaciones realizadas en la década de los años 30, dentro del marco de la denominada Escuela de Relaciones Humanas.

Las investigaciones se iniciaron en un pequeño pueblo llamado Hawthorne de la costa oeste de los Estados Unidos, en una planta dedicada a la fabricación de componentes eléctricos denominada Western Electric, la que emprendió la dedicada tarea de mejorar la productividad de sus empleados.

\section{Las Pruebas Experimentales}

Desde 1923 hasta 1934 , época en que fueron suspendidas las pruebas debido a la crisis financiera norteamericana del año 1929, un grupo de especialistas al mando de Elton Mayo aplicó en la Western Electric diferentes experimentos que modificaron las condiciones de trabajo con el fin de determinar un escenario que lograra optimizar el rendimiento del personal.

Por ejemplo, entre los factores tomados en cuenta como variables que probablemente incidían en la productividad se señalaron la iluminación de los ambientes, la altura y diseño de los bancos de trabajo, la música funcional, el color de los ambientes, entre otros. Pero, fue el experimento de la iluminación el que remarcó el extraordinario descubrimiento. Dos grupos de operarios señalados para la prueba que hacían la misma operación en condiciones laborales idénticas fueron escogidos para la misma experiencia: un grupo de observación trabajó bajo intensidad de luz variable mientras que el grupo de control, que era el seleccionado, trabajó bajo intensidad de luz constante. Se pretendía conocer el efecto de la iluminación sobre el rendimiento de los operarios.

Los resultados mostraron una relación directa. A mayor iluminación, mayor productividad de los operarios, dejándose constancia de los resultados de las pruebas que parecían bastante razonables.

Pero los resultados no quedaron allí, uno de los consultores decidió hacer el experimento en sentido inverso; es decir, analizar la prueba de iluminación disminuyendo la intensidad de la luz. Para sorpresa de los especialistas se encontró que las condiciones de productividad no variaban y que los trabajadores igualmente seguían elevando su rendimiento personal, luego, se infirió que la intensidad de la luz no afectaba el rendimiento personal. Se hizo entonces la pregunta ¿qué era lo que estimulaba a los trabajadores?

\section{$L a$ respuesta}

Para encontrar respuesta a los sucesos experimentados, Mayo y su equipo llegaron a una conclusión preliminar: los trabajadores respondían por la atención que los jefes centraban sobre su esfuerzo. La percepción que tenía el obrero de una mayor preocupación por parte de la dirección hacia ellos los motivaba, dando como consecuencia la respuesta de conseguir los resultados que la empresa esperaba: el optimizar el rendimiento.

Más adelante otros estudios condujeron a resultados similares, pero no fue sino hasta la década de los años 60 que se valoró la real dimensión de lo experimentado en Hawthorne, cuando Douglas McGregor 
resumió la experiencia en una frase luego de su análisis que dio lugar a su famosa Teoría $\mathrm{Xe} \mathrm{Y} \mathrm{"El} \mathrm{hombre} \mathrm{gusta} \mathrm{de} \mathrm{trabajar,} \mathrm{siempre}$ y cuando reciba satisfacciones de orden psicológico". Aquella conclusión fue trascendente porque se constituyó desde entonces en la base de la disciplina del management.

\section{LA GÉNESIS DEL TÉRMINO MANAGEMENT: ARTE Y CIENCIA DE DIRIGIR}

La palabra Management es de las que presentan muchas dificultades semánticas. Su origen es muy controvertido.
Para algunos, esta palabra tiene probablemente la misma raíz latina que la palabra francesa "menagement" cuyo significado es "disponer, regular con cuidado". Pero esta raíz también se asemeja mucho a la palabra italiana "maneggiaare" o a la catalana "manegar"que tiene el sentido de hacer las cosas con habilidad y destreza. Sin embargo, comúnmente se acepta como una palabra anglosajona, que suele traducirse al castellano de muy diversas maneras, como dirección, gestión, o gerencia empresarial. Personalmente, creo que el management posee un concepto y una función mucho más amplia que el expresado en éstos términos.

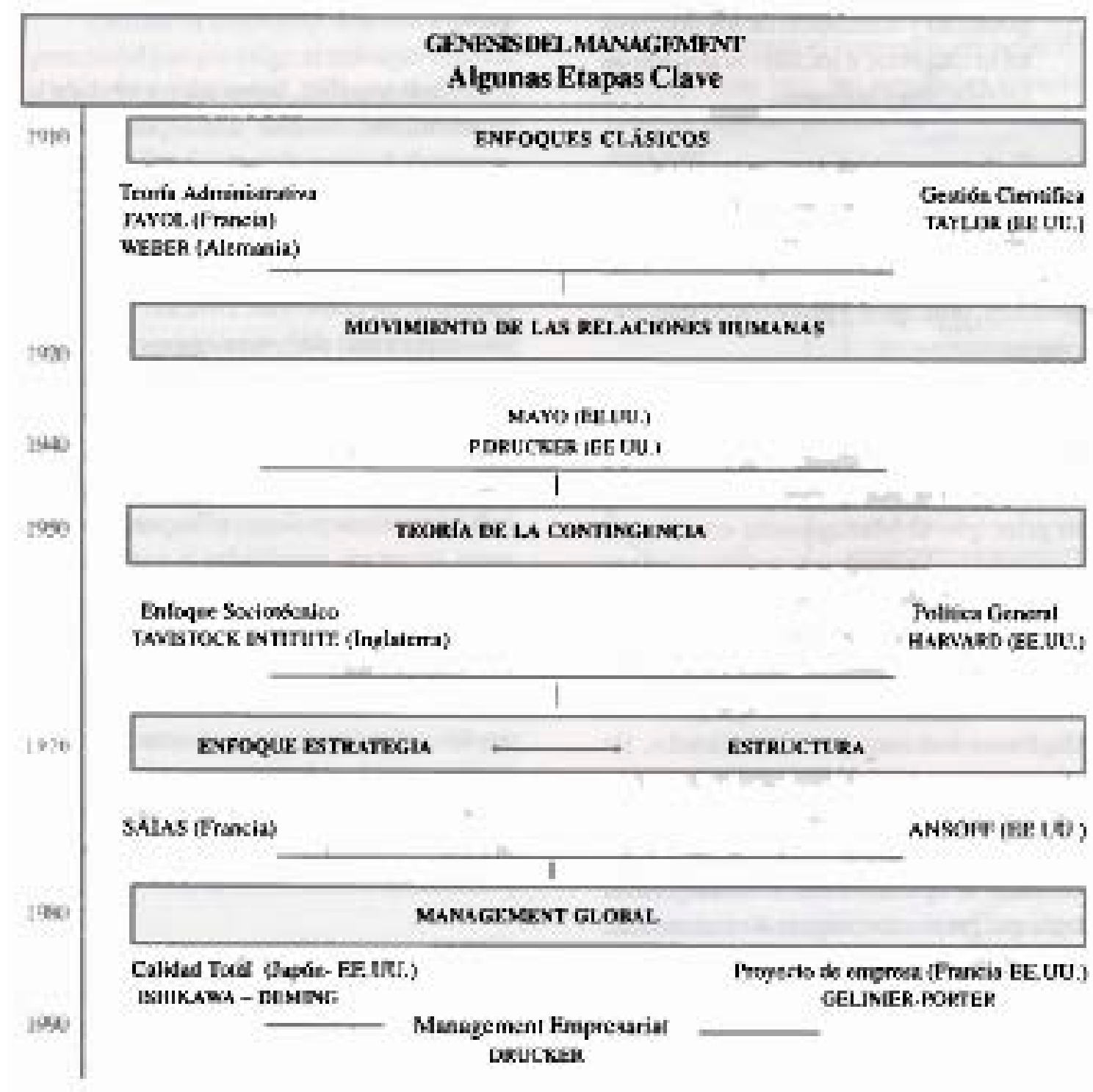


Su significado y contenido ha sufrido una gran variación a través del tiempo como observamos en la gráfica.

Así para algunos diccionarios la noción de Management puede tener las acepciones de:

- La función de autoridad jerárquica más alta de la empresa (el Manager con mayúscula).

- La identificación del término Management con diferentes cuadros directivos (en el sentido de mandos técnicos de la empresa).

- La utilización del Management como gobierno y animación de los hombres en la empresa, e incluso la gestión de las relaciones humanas.

Todas estas nociones corresponden a una idea técnica del management que debería ser superada hoy en día, pues el Management es un conjunto pluridisciplinario de gestiones, principios y procesos de transformación.

La verdad es que la función del Management ha variado tanto como su significado. Por eso, si bien es cierto que en un principio el Management creció y se desarrolló en las empresas manufactureras de fines del Siglo XIX y principios del XX, hoy es una práctica común en multitud de instituciones con carácter empresarial y no empresarial, tales como congregaciones religiosas e incluso organismos oficiales. En todos los sectores de la sociedad se ha vuelto imprescindible el Management para realizar deseos, alcanzar esperanzas y hacer que las ilusiones se operativicen. El Management logra que personas comunes alcancen metas y objetivos extraordinarios.

\section{¿QUÉ ES ELMANAGEMENT?}

Si hay alguien con la autoridad y los conocimientos necesarios para responder esta pregunta y dar una visión actual y unificadora, aphcable a toda clase de empresas e instituciones, es Peter Drucker, considerado unánimemente como el padre del Management moderno. Él definió este concepto de la siguiente manera: "Management es definir la misión de la empresa y motivar y organizar las energías humanas a fin de cumplirla" "...definir la misión de la empresa es parte entrepreneurial y gestionar, motivar y organizar las energías humanas es la parte relacionada con el liderazgo. Ambas, componen el management".

En la sencillez, la precisión y también la profundidad de este concepto, está la esencia de lo que realmente significa dirigir y de lo que implica ser un management.

Porque a pesar del tiempo y de los cambios, tal como dice Drucker "La tarea fundamental del management sigue siendo la misma: hacer que las personas puedan ser capaces de desarrollar una acción conjunta al darles objetivos comunes, la estructura correcta y el continuo adiestramiento y desarrollo que precisan para alcanzar resultados y enfrentar el cambio".

Así, a pesar del enorme avance cultural y tecnológico es "el management el que explica el porqué, por primera vez en la historia del hombre podemos emplear un gran número de personas con conocimiento y preparadas en un trabajo productivo".

Dirigir una nación, un hospital, una universidad, o una institución del tipo que sea, requiere básicamente de lo mismo que necesitamos para dirigir una empresa, ya que 
cualquier institución no es otra cosa que una empresa humana, tal como se decía antes, que tiene una finalidad, un propósito y una misión que cumplir. Sin un propósito compartido no hay empresa, ni hay nada. La misión es lo que da entidad y razón de ser a cualquier asociación humana.

Por tanto, la primera tarea del manager es definir la misión de la empresa, tal como lo expresa Drucker. Y para definirla correctamente, hay que orientarse absolutamente hacia el exterior de la propia empresa. Hacia el mercado y los clientes, en el caso de la empresa comercial, y hacia la sociedad en el caso de las instituciones de servicio.

Definir la misión es una tarea entrepreneurial porque exige al manager innovar y hacer frente al cambio. Ninguna institución humana es eterna, todas cambian con el transcurso del tiempo y según las circunstancias del entorno. Lo mismo ocurre con la misión, hay que redefinirla y actualizarla periódicamente.

El management debe tener capacidad de análisis y síntesis para saber qué está sucediendo en el entorno ¿qué cambios o circunstancias nuevas son problemas?, ¿cuáles son oportunidades?, ¿qué es necesario mantener? y ¿qué es preciso cambiar?, etcétera.

En función de estos conocimientos, el management habrá de tomar decisiones, generar objetivos y verificar su cumplimiento, controlando los resultados. En este sentido, debe ser un entrepreneurial, un innovador y estar polarizado hacia las oportunidades y los resultados. Para esto hace falta conocer y utilizar herramientas analíticas.

Pero a continuación -y esto es realmente importante-hay que conseguir que todos los miembros de la organización conozcan la misión, participen de ella, la asuman como propia y sepan cómo pueden contribuir con sus capacidades para hacerla posible. Esta es la parte relacionada con el liderazgo.

La motivación, la estructura organizativa y toda aquella actividad que tiene que ver con la conducción de la gente que trabaja dentro de la organización y con sus valores humanos, es lo que hará que la misión no sea una simple utopía, un deseo o una aspiración, sino lo que da sentido a la actividad por el bien de alguien.

\section{CONCLUSIÓN}

En resumen y culminando tan sólo queda concretar el concepto esencial del management bajo las siguientes características básicas graficadas de la manera siguiente:

\section{CONCEPTO DEL MANAGEMENT}

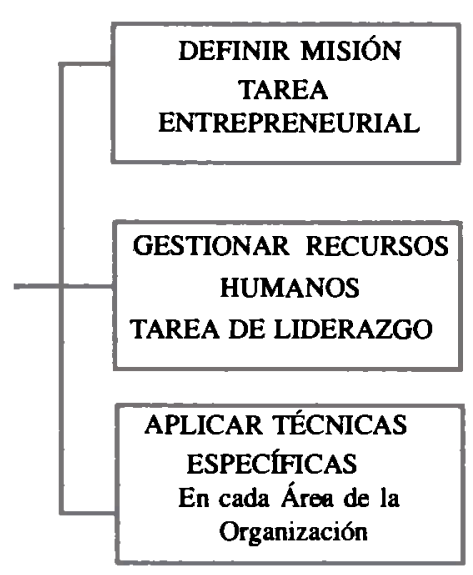

Estas son las tres características fundamentales del management, las cuales se deben contemplar formando una totalidad interrelacionada. Pero es realmente preocupante ver cómo en muchos libros se reduce el concepto de management a la aplicación de las técnicas específicas, dejando de considerar las otras dos características, a pesar de ser mucho más esenciales y necesarias. 
Por lo tanto, el Management; como arte de gobernar, no es una ciencia rigurosa al estilo de las matemáticas, sino más bien una disciplina práctica al igual que la medicina, donde la prueba no está centrada en demostrar si el tratamiento es científico, sino en descubrir si el paciente se recupera.

\section{BIBLIOGRAFÍA}

CHIAVENATTO, Idalberto

1993. "Introducción a la teoría general de la administración". Tercera Edición. Mc Graw Hill Interamericana, Bogotá.

HARVARD, Deustuo

2000. Business Review No.95 - marzo -

abril

OCEÁNO, GRUPOEDITORIALS.A

1998. Enciclopedia del Management.

PALOM IZQUIERDO, Francisco/ TORT RAVENTOS, Lluis

1991."Management en organizaciones al servicio del progreso humano". Espasa Calpe-C.D.N. - Ciencias de la Dirección.

PALOM IZQUIERDO, Francisco

1989. "Management: La tecnología punta del mando". Marcombo Boixarey Editores, España.

HERMEL, Philippe 1990."Management participativo". Ediciones Gestión 3000 S.A., Barcelona. 